\title{
Diabetic kidney disease in patients with type 2 diabetes mellitus: a cross-sectional study
}

\author{
Randa I. Farah ${ }^{1 *}$ D, Mohammed Q. Al-Sabbagh², Munther S. Momani ${ }^{1}$, Asma Albtoosh', Majd Arabiat ${ }^{1}$, \\ Ahmad M. Abdulraheem², Husam Aljabiri and Mohammad Abufaraj ${ }^{3,4}$
}

\begin{abstract}
Aim: Diabetic kidney disease (DKD) is a major long-term complication of diabetes mellitus (DM). Given the paucity of data on DKD in Jordan, we aimed to evaluate the prevalence, characteristics and correlates of DKD in Jordanian patients with type 2 DM.

Methods: This cross-sectional study included 1398 adult patients with type 2 DM who sought medical advice in the endocrinology clinic between March and September 2019. Demographic, clinical and laboratory data were reviewed. DKD was defined as reduced eGFR, and/or albuminuria. Three regression models were constructed to identify factors associated with CKD stages, albuminuria and DKD.

Results: Overall, 701 (50.14\%) patients had DKD, with a median age of $59.71 \pm 11.36$ years. Older age, high triglycerides, and low high-density lipoprotein were associated with DKD (multivariable odds ratio [OR]: 1.02, 95\% confidence interval [Cl]: 1.01-1.03, $p<0.01$; OR: 1.1, 95\% Cl: 1.01-1.2; and OR: 0.98, 95\% Cl: 0.97-0.99, $p<0.01$ respectively). Metformin and renin-angiotensin system blockers were negatively associated with albuminuria and chronic kidney disease stages $(p<0.01)$.

Conclusion: Our study demonstrated that approximately one half of patients with type 2 DM had DKD. Further studies are necessary to understand this high prevalence and the underlying factors. Future research are needed to assess implementing targeted community-based intervention.
\end{abstract}

Keywords: DKD, Albuminuria, Type 2 DM, Metformin, Dyslipidemia

\section{Introduction}

Worldwide, diabetes mellitus (DM) is a growing healthcare challenge and imposes a heavy burden on public health [1]. DM type 2 accounts for more than $90 \%$ of diabetes cases, and there is a rising number of people diagnosed with diabetes type 2 [1] with more rapid increase in low- and middle-income countries than in high-income countries [2].

\footnotetext{
* Correspondence: r.farah@ju.edu.jo

'Department of Internal Medicine, School of Medicine, University of Jordan, Amman, Jordan

Full list of author information is available at the end of the article
}

Diabetic kidney disease (DKD) is a major long-term complication of DM type 2 and is the leading cause of chronic kidney disease (CKD) and end-stage kidney disease (ESKD) worldwide [3]. Although renal biopsy is the gold standard to diagnose diabetic nephropathy, the majority of diabetic patients do not undergo kidney biopsy, as they are presumed to have diabetic kidney disease based upon clinical history and laboratory evaluation and because of invasive nature of kidney biopsy [4]. Furthermore, an increasing number of DM type 2 patients present with DKD [5]. The incidence and rate of DKD are less clear in DM type 2 than in type 1, mainly due to

C C The Author(s). 2021 Open Access This article is licensed under a Creative Commons Attribution 4.0 International License, which permits use, sharing, adaptation, distribution and reproduction in any medium or format, as long as you give appropriate credit to the original author(s) and the source, provide a link to the Creative Commons licence, and indicate if changes were made. The images or other third party material in this article are included in the article's Creative Commons licence, unless indicated otherwise in a credit line to the material. If material is not included in the article's Creative Commons licence and your intended use is not permitted by statutory regulation or exceeds the permitted use, you will need to obtain permission directly from the copyright holder. To view a copy of this licence, visit http://creativecommons.org/licenses/by/4.0/. The Creative Commons Public Domain Dedication waiver (http://creativecommons.org/publicdomain/zero/1.0/) applies to the data made available in this article, unless otherwise stated in a credit line to the data. 
the highly variable age of onset and difficulty in defining the exact time of onset and associated comorbidities [6].

There are marked racial differences in the epidemiology of DKD, which could be partially explained by the differences in health care services and environmental factors such as dietary intake and smoking [6]. Studying the prevalence and factors associated with DKD in patients with DM type 2 is crucial to estimate the disease's burden and modifiable risk factors and to set research priorities. The urbanization, rapid change in the lifestyle and the dramatic increase in type 2 diabetes prevalence in Jordan necessitate evaluating the consequences of this disease, such as DKD [2].

Although the prevalence of DM type 2 in Jordan has been shown to be on the rise [2], the prevalence of DKD risk factors has not been well elucidated. Moreover, a focused study on DKD degree/severity among those with DM type 2 in Jordan has not been reported. Therefore, we aim to evaluate the prevalence, characteristics, and risk factors of DKD in patients with DM type 2 in Jordan. These findings will help define priorities and establish health policies on the national level and aid in patient counseling and treatment planning.

\section{Materials and methods}

\section{Study population}

This cross-sectional study aimed to assess the prevalence of DKD among patients aged $>18$ years who were diagnosed with type 2 diabetes and sought medical advice at the University of Jordan Hospital, Endocrinology clinic, between March and September 2019. We excluded patients with missing data (those that did not have at least two readings of serum creatinine or those that did not have at least two readings of urine albumin protein within 6 months of the assigned clinic visit), ESKD on dialysis, and other possible causes of CKD or proteinuria. Informed consent was obtained from all participants. This study was approved by the University of Jordan Institutional Review Board and followed the institutional and/or national research committee's ethical standards and the principles of the World Medical Association Declaration of Helsinki.

\section{Data collection and evaluations}

Patients diagnosed with DM type 2 were identified according to patients' medical records and verified during their clinic visits by an assigned research assistant. The following data were collected via face-to-face interviews and referral to medical charts by a trained research assistant: medical history including hypertension, myocardial infarction, coronary artery disease, heart failure, stroke, and the onset of diabetes; current diabetes status with complications such as retinopathy, peripheral neuropathy, and cardiovascular disease as reported during the interview; data on glycemic control, i.e., latest values of fasting blood glucose and hemoglobin A1c (HbA1c); and smoking status. Current medication usage, such as antidiabetics, antihypertensives, lipid-lowering agents, and other medications, taken by the patients was also reviewed. A trained research assistant performed the following measurements in the office: blood pressure (mean of two consecutive measurements of systolic and diastolic blood pressure in the sitting position, 3-4 min apart) and we considered abnormal blood pressure reading $>140 \mathrm{mmHg}$ systolic and $>90 \mathrm{mmHg}$ diastolic, height, weight, and waist circumference. We also collected data on HbA1c, fasting blood sugar, fasting lipid profile (if available) as we considered abnormal results as following: High density lipoprotein (HDL $<38 \mathrm{mg} / \mathrm{dl}$ in men and $<50 \mathrm{mg} / \mathrm{dl}$ in women) and high triglyceride $>160 \mathrm{mg} / \mathrm{dl}$ and Low density lipoprotein (LDL) $>100 \mathrm{mg} / \mathrm{dl}$, and serum albumin levels up to 3-6 months from the clinic visit using the latest blood test results when available. We assessed the kidney function using serum creatinine and urinary albumin excretion measurements on two occasions at least 3 months apart. We excluded patients who did not have 2 readings of any of the kidney function assessment within 6 months of the assigned clinic visit.

The estimated glomerular filtration rate (eGFR) was determined for each patient using a standardized serum creatinine level and the Chronic Kidney Disease Epidemiology Collaboration formula. Increased urinary albumin excretion was diagnosed as 1) microalbuminuria, if the urinary albumin to creatinine ratio (ACR) was $\geq 30$ and $\leq 300 \mathrm{mg} / \mathrm{g}$ or the protein to creatinine ratio (PCR) was $>0.150$ and $<0.500 \mathrm{~g} / \mathrm{g}$ or 2) macroalbuminuria, if the ACR was $\geq 300 \mathrm{mg} / \mathrm{g}$ or the PCR was $>0.500 \mathrm{~g} / \mathrm{g}$, and 3) albuminuria indicated patients with either micro- or macroalbuminuria $[7,8]$. Urine samples that were positive for leucocytes and nitrites, which are indicative of significant urinary tract infection, and erythrocyte or $\mathrm{Hb}$ levels of $\geq 5$ counts $/ \mu \mathrm{L}$, which is indicative of significant hematuria (false positives), were excluded.

DKD was defined as a reduced eGFR, $<60 \mathrm{~mL} / \mathrm{min} /$ $1.73 \mathrm{~m}^{2}$, and/or increased urinary albumin excretion, $\geq 30 \mathrm{mg} / \mathrm{g}$ creatinine that persisted for $\geq 3$ months in the presence of longstanding diabetes and exclusion of other causes of CKD.

\section{Statistical analysis}

All analyses were performed using STATA (Stata Statistical Software: Release 16. College Station, TX, StataCorp LLC). Categorical variables are presented as percentages, while continuous variables are presented as the mean \pm standard deviation.

Differences in sociodemographic characteristics, past medical history, comorbidities, and medications among 
patients with or without evidence of DKD were assessed using the chi-square test for categorical variables and Student's t-test continuous variables. Three regression models were constructed: (i) to identify variables associated with CKD stages, a multistage ordinal logistic regression analysis was used, (ii) to assess variables associated with the degree of albuminuria, a multistage ordinal logistic regression analysis was used, and (iii) finally, a binary logistic regression was used to assess the variables associated with an increased risk of DKD. The confidence interval was set at $95 \%$, and $p$-values of $\leq 0.05$ were considered to indicate statistical significance.

\section{Results}

Among 1652 patients, 1398 patients met our inclusion criteria. The median age was $59.71 \pm 11.36$ years, there were 573 men $(40.99 \%)$ and 825 women $(59.01 \%)$, and the median duration of DM type 2 was $10.42 \pm 7.99$ years. Further, $970(69.38 \%)$ patients in our study population were hypertensive with a mean systolic blood pressure of $135.53 \pm 21.37 \mathrm{mmHg}$, and the mean diastolic blood pressure was $77.72 \pm 13.61 \mathrm{mmHg}$. A body mass index (BMI) of $>30$ was identified in $66 \%$ of the population. The mean HbA1c level was $7.71 \% \pm 1.60 \%$. Retinopathy was documented in 477 patients (34.12\%). These baseline characteristics of our study population are summarized in Table 1.

We found that 701 (50.14\%) patients had DKD, 625 (44.7\%) had albuminuria, and 268 (19.17\%) had CKD with an eGFR of $<60 \mathrm{~mL} / \mathrm{min} / 1.73 \mathrm{~m}^{2}$.

DKD and a reduced eGFR were more prevalent among patients aged $>60$ years $(p<0.001)$ (Fig. 1$)$. Such an association was not detected for microalbuminuria or albuminuria $(p=0.53)$. We also found that patients with DKD were more likely to have had used insulin, metformin, and renin-angiotensin system (RAAS) blockers $(p<$ $0.01)$ than were those without DKD $(p<0.05)$ (Table 1).

On univariate analysis comparing patients with DKD to those without DKD, we found age $>60$ years, longer duration of diabetes, higher HbA1c of $>7 \%$, and hypertension were correlated to DKD $(p<0.0001)$. DKD was also associated retinopathy and neuropathy $(p<0.01)$.

Table 2 shows the multivariable analysis assessing factors associated with diabetic kidney disease. Age older than 60 year was associated with DKD (multivariable odds ratio [OR]: 1.02, 95\% confidence interval [CI]: $1.01-1.03, p<0.01)$. Retinopathy, neuropathy, high triglyceride levels, and low high-density lipoprotein (HDL) levels were also correlated with DKD (OR: 1.27, 95\% CI: 1.01-1.6, $p<0.05$; OR: $1.3,95 \%$ CI: $1.01-1.7, p<0.05$; OR: $1.1,95 \%$ CI: $1.01-1.2, p<0.01$; and OR: $0.98,95 \%$ CI: $0.97-0.99, p<0.01$; respectively). Metformin was negatively correlated with DKD (OR: 0.42 , 95\% CI: 0.31$0.55, p<0.01)$. The use of insulin, beta blockers, calcium channel blockers, and diuretics was also significantly associated with DKD (OR: 1.3, 95\% CI: 1.1-1.7, $p=0.01$; OR: $1.3,95 \%$ CI: $1.01-1.7, p=0.02$; OR: $1.4,95 \% \mathrm{CI}$ : $1.1-1.9, p<0.01$; and OR: $1.4,95 \%$ CI: $1.1-1.8, p=0.01$; respectively) (Table 2).

Advanced CKD was significantly associated with older age and diabetes duration ( $\beta$ coefficient: 0.06 and 0.03 , $p<0.01$ and $<0.04$, respectively). It was also strongly associated with the use of beta-blockers, diuretics, and calcium channel blockers ( $\beta$ coefficient: $0.35,0.6$, and 0.7 , respectively; $p<0.01$ for all three factors). We observed that RAAS blocker and metformin use were negatively associated with advanced CKD stage ( $\beta$ coefficient: 0.31 and -1.34 , respectively; $p<0.01$ for both factors) (Table 3).

Higher albuminuria levels were associated with calcium channel blocker and insulin use ( $\beta$ coefficient: 0.49 and $p<0.01$ ). Hypertension and high triglyceride levels were associated with higher albuminuria levels ( $\beta$ coefficient: 0.33 and $0.02 ; p=0.03$ and $<0.01$, respectively). The use of Metformin and RAAS blocker was negatively associated with the presence of albuminuria ( $\beta$ coefficient: -0.6 and -0.33 , respectively; $p<0.01$ ). The serum albumin level was associated with the degree of albuminuria (a higher serum albumin level was associated with a higher degree of albuminuria) $(p<0.01)$ (Table 4$)$.

According to the Kidney Disease: Improving Global Outcomes guidelines, we categorized kidney function into CKD-G and CKD-A stages based on the eGFR and ACR [9]. We found that $29.3 \%$ of the study population had a moderate risk for all major outcomes [9] (Fig. 2) and that $5.4 \%$ of our patients (76 patients) had nonalbuminuria DKD.

\section{Discussion}

We found that approximately half of the diabetic patients visiting the endocrinology clinic had DKD. The prevalence of DKD was related to age, ranging from $46 \%$ in patients aged $<60$ to $52.8 \%$ in those aged $>60$ years. The following factors were significantly correlated with DKD: older age ( $>60$ years), diabetic microvascular and macrovascular complications, and dyslipidemia. Metformin and RAAS blockers were associated with a lower degree of albuminuria and less advanced CKD.

Our results were in line with the reported prevalence of DKD in the Middle East (33-54.1\%) [10, 11]. These studies relied on albuminuria to define DKD and this potentially underestimated the prevalence of DKD in some reports [12-14]. The reported overall prevalence in our study was also in line with that reported in the US (54\%) [15]. Nevertheless, the prevalence of DKD in younger patients in the US were found to be approximately $25 \%$, as compared with $46 \%$ in our population [15]. The higher prevalence of DKD in younger patients 
Table 1 Patient's characteristics according to diabetic kidney disease status

\begin{tabular}{|c|c|c|c|c|c|}
\hline \multirow[t]{2}{*}{ Variable } & \multirow[t]{2}{*}{ Category } & \multirow{2}{*}{$\begin{array}{l}\text { n (\%) } \\
1398(100)\end{array}$} & \multirow{2}{*}{$\begin{array}{l}\text { DKD n (\%) } \\
701(50.14)\end{array}$} & \multirow{2}{*}{$\begin{array}{l}\text { Non-DKD n (\%) } \\
697(49.86)\end{array}$} & \multirow[t]{2}{*}{$p$-value } \\
\hline & & & & & \\
\hline \multirow[t]{2}{*}{ Age (Years) } & $<60$ & $646(46.21)$ & $289(41.23)$ & $357(51.22)$ & $<0.01^{*}$ \\
\hline & $\geq 60$ & $752(52.79)$ & $412(58.77)$ & $340(48.78)$ & \\
\hline \multirow[t]{2}{*}{ Sex } & Male & $572(41)$ & $287(41)$ & $286(41)$ & 0.97 \\
\hline & Female & $825(59)$ & $414(59)$ & $411(59)$ & \\
\hline \multirow[t]{3}{*}{ Duration of DM } & $<5$ years & $393(28.1)$ & $162(23.1)$ & $231(33.1)$ & $<0.01^{*}$ \\
\hline & $5-10$ years & $304(21.8)$ & $142(20.3)$ & $162(23.23)$ & \\
\hline & $>10$ years & $701(50.1)$ & $397(56.6)$ & $304(43.6)$ & \\
\hline \multirow[t]{2}{*}{$\mathrm{HbA1c}(\%)$} & $<7.0$ & $547(39.1)$ & $248(35.4)$ & $299(42.9)$ & $<0.01^{*}$ \\
\hline & $\geq 7.0$ & $851(60.9)$ & $453(64.6)$ & $398(57.1)$ & \\
\hline \multirow[t]{3}{*}{ Antidiabetic medications } & Insulin & $691(49.5)$ & $389(55.6)$ & $302(43.4)$ & $<0.01^{*}$ \\
\hline & Metformin & $1074(76.9)$ & $475(67.9)$ & $500(86)$ & $<0.01^{*}$ \\
\hline & Other anti-diabetics & $624(44.7)$ & $308(44)$ & $316(45.4)$ & 0.6 \\
\hline Using RAAS blockers & & $737(52.8)$ & $388(55.4)$ & $349(50.1)$ & $<0.05^{*}$ \\
\hline Waist circumference $(\mathrm{cm})$ & & $109.3 \pm 14.6^{*}$ & $110.2 \pm 14.6^{*}$ & $108.4 \pm 14.6^{*}$ & $0.02^{*}$ \\
\hline \multirow[t]{3}{*}{ BMI } & $<25$ & $121(8.7)$ & $58(8.3)$ & $63(9)$ & 0.87 \\
\hline & $25-29$ & $353(25.3)$ & $176(25.2)$ & $177(25.5)$ & \\
\hline & $>30$ & $920(66)$ & $464(66.5)$ & $456(65.5)$ & \\
\hline \multirow[t]{3}{*}{ Smoking } & Never smoker & $986(70.5)$ & $488(69.6)$ & $498(71.5)$ & 0.18 \\
\hline & Current smoker & $175(12.5)$ & $99(14.1)$ & $76(11)$ & \\
\hline & Ex-smoker & $237(17)$ & $114(16.3)$ & $123(17.5)$ & \\
\hline Medical history & Hypertension & $970(69.4)$ & $540(77)$ & $430(61.7)$ & $<0.01^{*}$ \\
\hline \multirow[t]{6}{*}{ Medical history } & Myocardial infarction & $154(11)$ & $91(13)$ & $63(9)$ & $0.02^{*}$ \\
\hline & Congestive heart failure & $46(3.3)$ & $26(3.7)$ & $20(2.9)$ & 0.38 \\
\hline & Coronary artery disease & $155(11.1)$ & $92(13.1)$ & $63(9)$ & $0.02^{*}$ \\
\hline & Stroke & $97(6.9)$ & $64(9.1)$ & $33(4.7)$ & $0.01^{*}$ \\
\hline & Neuropathy & $596(42.66)$ & $330(47.1)$ & $266(38.2)$ & $0.01^{*}$ \\
\hline & Retinopathy & $477(34.1)$ & $289(41.2)$ & $188(27)$ & $<0.01^{*}$ \\
\hline
\end{tabular}

*Mean \pm standard deviation

$D K D$ diabetic kidney disease, DM diabetes mellitus, RAAS blockers, BMI body mass index

*Statistically significant

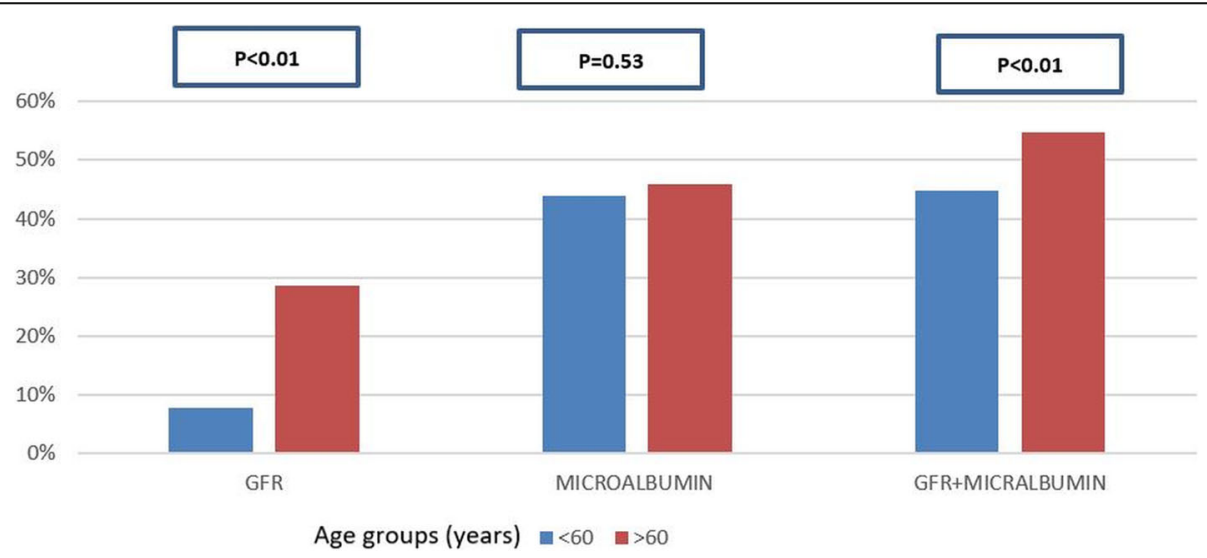

Fig. 1 Proportion of patients with eGFR $<60 \mathrm{~mL} / \mathrm{min} / 1.73 \mathrm{~m}^{2}$ or albuminuria, by age groups 
Table 2 Multivariate binary logistic regression analyses for factors associated with diabetic kidney disease

\begin{tabular}{|c|c|c|c|c|}
\hline Variable & Subgroups & OR & $95 \% \mathrm{Cl}$ & $p$ value \\
\hline \multirow[t]{2}{*}{ Sex } & Female (Ref) & & & \\
\hline & Male & 0.9 & $0.7-1.12$ & 0.6 \\
\hline Age (Years) & & 1.02 & $1.01-1.03$ & $0.02^{*}$ \\
\hline Duration of DM (Years) & & 1.1 & $0.99-1.03$ & 0.42 \\
\hline \multicolumn{5}{|l|}{ Medical history } \\
\hline Smoking & & 1.12 & $0.95-1.3$ & 0.17 \\
\hline Hypertension & & 1.4 & $1.1-1.8$ & $0.03^{*}$ \\
\hline CAD & & 0.9 & $0.6-1.3$ & 0.44 \\
\hline \multirow[t]{3}{*}{ Stroke } & & 1.4 & $0.9-2.2$ & 0.16 \\
\hline & Neuropathy & 1.24 & $1.01-1.6$ & $<0.05^{*}$ \\
\hline & Retinopathy & 1.3 & $1.01-1.7$ & $<0.05^{*}$ \\
\hline \multirow[t]{6}{*}{ Medications } & Insulin & 1.38 & $1.1-1.7$ & $0.01^{*}$ \\
\hline & Metformin & 0.42 & $0.33-0.55$ & $<0.01^{*}$ \\
\hline & ACEIs/ARBs & 0.8 & $0.6-1.1$ & 0.1 \\
\hline & Beta blockers & 1.3 & $1.01-1.7$ & $0.02^{*}$ \\
\hline & Diuretics & 1.4 & $1.1-1.8$ & $0.01^{*}$ \\
\hline & $\mathrm{CCB}$ & 1.4 & $1.1-1.9$ & $<0.01^{*}$ \\
\hline Triglyceride's level (mg/dl) & & 1.1 & $1.01-1.2$ & $<0.01^{*}$ \\
\hline HDL (mg/dl) & & 0.98 & $0.97-0.99$ & $<0.01^{*}$ \\
\hline
\end{tabular}

$O R$ odds ratio, $C l$ confidence interval, $D M$ diabetes mellitus, $C A D$ coronary artery disease, $A C E l$ angiotensin converting enzyme inhibitor, $A R B$ angiotensin receptor blocker, $C C B$ calcium channel blocker, $H D L$ high-density lipoprotein *Statically significant is alarming and might result in a public health crisis in the coming years if active intervention is not performed.

The prevalence of DKD increases with age and is more evident by a low eGFR than by albuminuria. This can be explained by the physiological decline in renal function with age, which is associated with a gradual decline in eGFR [16]. This observation was confirmed in our study, wherein the impairment of eGFR with age was more marked than the occurrence of albuminuria.

Our results showed that patients who reported using metformin or RAAS blocker had a lower risk of developing DKD and proteinuria. Metformin is the preferred treatment option for DM type 2 and we found that metformin was negatively associated with DKD, albuminuria, and advanced CKD, consistent with most of the observational studies reporting that metformin is associated with reduced progression to ESKD in type 2 diabetes patients with DKD. However, the reason for these observations remains unknown [17]. In most animal model studies, metformin has shown prominent inhibitory effects on tubulointerstitial fibrosis in both diabetic and non-diabetic models [18]. Further, the long-term benefits of metformin regarding ESKD and cardiovascular disease in patients with moderate CKD have been demonstrated. To achieve the maximal renoprotective benefits of metformin, it may be necessary to use metformin in combination with SGLT2 (Sodium-Glucose co-transporter-2) inhibitors or incretin-based therapies at an early stage of DKD [19]. Unfortunately, metformin

Table 3 Multivariable ordinal logistic regression analyses evaluating the correlates of chronic kidney disease and its stage

\begin{tabular}{|c|c|c|c|c|}
\hline Variable & Subgroups & Beta coefficient & $95 \% \mathrm{Cl}$ & $p$ value \\
\hline \multirow[t]{2}{*}{ Sex } & Female (Ref) & & & \\
\hline & Male & -0.2 & $-0.41-0.1$ & 0.24 \\
\hline Age (Years) (continuous) & & 0.06 & $0.05-0.07$ & $<0.01^{*}$ \\
\hline Duration of DM $(\mathrm{Y})$ (continuous) & & 0.02 & $0.01-0.03$ & $0.04^{*}$ \\
\hline \multirow[t]{6}{*}{ Medical history } & Smoking & -0.5 & $-0.21-0.12$ & 0.6 \\
\hline & Hypertension & 0.23 & $-0.07-0.54$ & 0.13 \\
\hline & $C A D$ & 0.12 & $-0.23-0.73$ & 0.5 \\
\hline & Stroke & 0.32 & $-0.1-0.7$ & 0.13 \\
\hline & Neuropathy & -0.1 & $-0.33-0.14$ & 0.4 \\
\hline & Retinopathy & 0.27 & $0.02-0.5$ & $0.04^{*}$ \\
\hline \multirow[t]{6}{*}{ Medications } & Insulin & 0.06 & $-0.2-0.31$ & 0.65 \\
\hline & Metformin & -1.34 & $-1.6--1.1$ & $<0.01^{*}$ \\
\hline & ACEIs/ARBs & -0.31 & $-0.56--0.10$ & $<0.01^{*}$ \\
\hline & Beta blockers & 0.35 & $0.1-0.6$ & $<0.01^{*}$ \\
\hline & Diuretics & 0.6 & $0.33-0.85$ & $<0.01^{*}$ \\
\hline & $\mathrm{CCB}$ & 0.7 & $0.44-1$ & $<0.01^{*}$ \\
\hline Triglyceride level (mg/dl) & & 0.01 & $0.0001-0.02$ & $<0.01^{*}$ \\
\hline
\end{tabular}

$C I$ confidence interval, $D M$ diabetes mellitus, $C A D$ coronary artery disease, $A C E I$ angiotensin converting enzyme inhibitor, $A R B$ angiotensin receptor blocker, $C C B$ calcium channel blocker

*Statically significant 
Table 4 Multivariable ordinal logistic regression analyses evaluating correlates of albuminuria

\begin{tabular}{|c|c|c|c|c|}
\hline Variable & Subgroups & Beta coefficient & $95 \% \mathrm{Cl}$ & $p$ value \\
\hline \multirow[t]{2}{*}{ Sex } & Female (Ref) & & & \\
\hline & Male & 0.05 & $-0.2-0.3$ & 0.7 \\
\hline Age $(Y)$ & & 0.01 & $-0.01-0.02$ & 0.4 \\
\hline Duration of DM (Y) & & 0.01 & $-0.02-0.03$ & 0.2 \\
\hline \multirow[t]{5}{*}{ Medical history } & Smoking & 0.1 & $-0.06-0.25$ & 0.24 \\
\hline & Hypertension & 0.33 & $0.04-0.6$ & $0.03^{*}$ \\
\hline & Stroke & 0.1 & $-0.33-0.5$ & 0.7 \\
\hline & Neuropathy & 0.07 & $-0.16-0.3$ & 0.53 \\
\hline & Retinopathy & 0.14 & $-0.1-0.4$ & 0.27 \\
\hline \multirow[t]{5}{*}{ Medications } & Insulin & 0.36 & $0.11-0.62$ & $<0.01^{*}$ \\
\hline & Metformin & -0.62 & $-0.88--0.36$ & $<0.01^{*}$ \\
\hline & ACEIs/ARBs & -0.33 & $-0.58--0.09$ & $0.01^{*}$ \\
\hline & Beta blockers & 0.22 & $-0.03-0.47$ & 0.08 \\
\hline & $C C B$ & 0.49 & $0.23-0.75$ & $<0.01^{*}$ \\
\hline Triglyceride's level (mg/dl) & & 0.02 & $0.01-0.03$ & $<0.01^{*}$ \\
\hline Albumin (g/dl) & & -0.7 & $-1.0--0.4$ & $<0.01^{*}$ \\
\hline
\end{tabular}

Cl confidence interval, DM diabetes mellitus, $A C E l$ angiotensin converting enzyme inhibitor, $A R B$ angiotensin receptor blocker, CCB calcium channel blocker *Statically significant

should be discontinued in cases of advanced CKD despite this favorable early effect.

Clinical trials have also demonstrated the beneficial effects of RAAS blockers in delaying the progression of DKD. Two large randomized long-term trials, the Angiotensin Antagonist Losartan study [20] and the Irbesartan Diabetic Nephropathy Trial [21] indicated that ARBs are effective in slowing the progression of diabetic nephropathy. These studies have shown that nephroprotection with ACE inhibitors and ARBs was greater than what might be expected due to a reduction in blood pressure. Our study found that RAAS blockers were negatively associated with a lower degree of albuminuria and advanced CKD stage. Many studies have shown that ACEIs and ARBs have beneficial renoprotective effects concerning the progression of DKD in

\begin{tabular}{|c|c|c|c|c|c|c|}
\hline & & $\begin{array}{l}\text { Persistent } \\
\text { categories }\end{array}$ & $\begin{array}{l}\text { buminuria/p } \\
\text { description a }\end{array}$ & $\begin{array}{l}\text { teinuria } \\
\text { d range) }\end{array}$ & & \\
\hline \multirow[t]{2}{*}{$\begin{array}{c}\text { GFR } \\
\text { categories }\end{array}$} & \multirow[t]{2}{*}{$\begin{array}{c}\text { eGFR } \\
\left(\mathrm{ml} / \mathrm{min} / 1.73^{2}\right)\end{array}$} & $\begin{array}{c}\mathrm{A} 1 \\
\begin{array}{c}\text { Normal to mild } \\
\text { increase }\end{array}\end{array}$ & $\begin{array}{c}\text { A2 } \\
\text { Moderately } \\
\text { increased }\end{array}$ & $\begin{array}{c}\text { A3 } \\
\text { Severely } \\
\text { increase }\end{array}$ & & \\
\hline & & $<30$ & $30-299$ & $>300$ & Total & \\
\hline G1 & $\geq 90$ & $485(34.7 \%)$ & $\begin{array}{c}249 \\
(17.8 \%)\end{array}$ & $37(2.6 \%)$ & $\begin{array}{c}771 \\
(55.1 \%)\end{array}$ & \multirow{3}{*}{$\begin{array}{l}\square \\
\text { Low risk } \\
\square \\
\text { Moderately } \\
\text { increase risk }\end{array}$} \\
\hline G2 & $60-89$ & $212(15.2 \%)$ & $113(8.1 \%)$ & $34(2.4 \%)$ & $\begin{array}{c}359( \\
25.7 \%)\end{array}$ & \\
\hline G3a & $45-59$ & $48(3.4 \%)$ & $47(3.4 \%)$ & $23(1.6 \%)$ & $\begin{array}{c}118 \\
(8.4 \%)\end{array}$ & \\
\hline $\mathrm{G} 3 \mathrm{~b}$ & $30-44$ & $17(1.2 \%)$ & $26(1.9 \%)$ & $34(2.4 \%)$ & $77(5.5 \%)$ & \multirow{4}{*}{$\begin{array}{l}\text { High risk } \\
\text { Very high } \\
\text { risk } \\
\text { Highest risk }\end{array}$} \\
\hline G4 & $15-29$ & $10(0.7 \%)$ & $10(0.7 \%)$ & $34(2.4 \%)$ & $54(3.9 \%)$ & \\
\hline \multirow[t]{2}{*}{ G5 } & $<15$ & $1(0.07 \%)$ & $1(0.07 \%)$ & $17(1.2 \%)$ & $19(1.4 \%)$ & \\
\hline & Total & $773(55.3 \%)$ & $446(32 \%)$ & $\begin{array}{c}179 \\
(12.8 \%)\end{array}$ & $\begin{array}{c}1398 \\
(100 \%)\end{array}$ & \\
\hline
\end{tabular}

Fig. 2 Risk categories of CKD according to 2012 KDIGO (Kidney Disease: Improving Global Outcomes) classification in subgroup of 1398 patients. Patients were categorized into each risk category based on eGFR value and severity of albuminuria 
hypertensive diabetic patients and can delay or prevent the development of diabetic nephropathy independently of the beneficial blood pressure-lowering effect in patients with DM type 2 and microalbuminuria [22, 23]. Subsequently, the National Kidney Foundation has recommended using that either ARBs or ACEIs in patients with diabetes regardless of the presence of hypertension.

Albuminuria is considered the first clinical symptom of DKD and is traditionally used as a screening test for DKD. However, mounting evidence suggests that the traditional concept of the natural history of DKD has changed, and a considerable proportion of adult diabetics are normoalbuminuric despite having a low eGFR [24]. The prevalence of normoalbuminuric DKD varies from 14.29 to $56.6 \%$ among diabetic patients of different ethnicities $[25,26]$. These findings have led the American Diabetes Association to recommend screening DKD based on albuminuria and eGFR to avoid missing cases. In our population, only $5.4 \%$ of patients had an eGFR of $<60 \mathrm{~mL} / \mathrm{min} / 1.73 \mathrm{~m}^{2}$ without evidence of albuminuria.

The association between hypertension and albuminuria is well established but the mechanism is still controversial. It is thought to be an endothelial dysfunction, which is strongly associated with increased cardiovascular risk, and causes renal manifestation. Hypertension is reported in approximately $70-80 \%$ of DM type 2 at the time of diagnosis and known to exacerbate diabetic nephropathy [27]. Our study also showed that hypertension was associated with higher degree of albuminuria and DKD in patients with DM type 2.

The association between dyslipidemia and the development of DKD was investigated in several studies, and many epidemiological studies demonstrated an association between diabetic dyslipidemia and DKD [28]. Posthoc analysis of large interventional studies of high-risk patients with diabetes $[29,30]$ revealed that high triglyceride and low HDL concentrations were associated with DKD. The ADVANCE study demonstrated that lower baseline HDL levels were a significant and independent predictor of DKD. In contrast, no association was found with the risk of diabetic retinopathy, suggesting that differences may exist in the pathophysiology of these microvascular complications [29]. The FELD study showed that the hypotriglyceridemic drug fenofibrate slowed the decline of renal function and reduced the degree of albuminuria in patients with DM type 2 [30]. Our study also showed that low HDL cholesterol levels and high triglyceride levels were associated with DKD.

There were several limitations to this study. First, the retrospective and the cross-sectional study design introduced recall bias and precluded temporal evaluation of risk factors and outcomes of interest. Therefore, a cause-effect relationship cannot be concluded. However, the data obtained by personal interviews and referring to medical charts minimized the recall bias and improved the data quality.

Second, our study was performed in a tertiary medical center and might not reflect the status-quo of diabetes in Jordan. Nevertheless, this tertiary center provides service to a wide range of patients with different socioeconomic backgrounds all over Jordan. Additionally, given the Jordanian population's unique composition, our findings can be generalized to the middle East. Third, this study had a small sample size for a common disease and did not examine the onset and the course of DKD in the population as the baseline readings of albuminuria and renal function at the time of diagnosis were not available.

\section{Conclusion}

We found that more than half of the patients with DM type 2 had DKD with approximately one-third were at moderate risk of major adverse events. DKD was correlated to older age, longer duration of diabetes, the presence of diabetic complications, and dyslipidemia. In addition, patients who were using metformin or RAAS blocker had a lower risk of DKD and proteinuria. Albuminuria adds valuable information regarding the prevalence, epidemiological characteristics, and risk factors of DKD. Prospective studies with long follow-up duration are needed to understand the natural course of DKD and future research should also focus on the effect of raising awareness about DKD in patients with DM type 2 to aid in implementing a more targeted communitybased intervention.

\section{List of Abbreviations}

DKD: Diabetic kidney disease; DM: Diabetes mellitus; CKD: Chronic kidney disease; ESKD: End-stage kidney disease; HbA1c: Hemoglobin A1c; eGFR: The estimated glomerular filtration rate; ACR: Urinary albumin to creatinine ratio; PCR: The protein to creatinine ratio; RAAS: Renin-angiotensin system; BMI: Blockers, body mass index

\section{Acknowledgements}

Not Applicable.

\section{Data availability}

The datasets used and/or analysed during the current study are available from the corresponding author on reasonable request.

\section{Disclosure statement}

The authors declare that they have no conflicts of interest.

\section{Author contribution}

Randa Farah and Majd Arbiate contributed to the conception, design of the work and the acquisition of data. Mohammad Abufaraj, Mohammed Q. AlSabbagh and Randa Farah contributed to data analysis and interpretation. Randa Farah, Munther S. Momani, Asma Albtoosh, Majd Arabiat, Ahmad Tarifi and Husam Aljabiri drafted the manuscript. Mohammad Abufaraj, Randa Farah and Mohammed Q. Al-Sabbagh critically revised the manuscript. All authors gave final approval and agreed to be accountable for all aspects of work ensuring integrity and accuracy.

Funding

The authors received no specific funding for this work. 


\section{Declarations}

\section{Ethical statement}

This retrospective study was approved by University of Jordan Hospital Institutional Review Board and all procedures performed were in accordance with the ethical standards of the institutional and/or national research committee and with the principles of the World Medical Association Declaration of Helsinki. Informed consent was obtained from all participants.

\section{Consent for publication}

NA/Not Applicable.

\section{Author details}

'Department of Internal Medicine, School of Medicine, University of Jordan Amman, Jordan. ${ }^{2}$ School of medicine, University of Jordan, Amman, Jordan. ${ }^{3}$ Division of Urology, Department of Special Surgery, Jordan University Hospital, The University of Jordan, Amman, Jordan. ${ }^{4}$ Department of Urology, Medical University of Vienna, Vienna, Austria.

Received: 14 February 2021 Accepted: 31 May 2021 Published online: 16 June 2021

\section{References}

1. https://www.who.int/news-room/fact-sheets/detail/diabetes

2. Brown DW, Mokdad AH, Walke H, As'ad M, Al-Nsour M, Zindah M, Arqoob K Belbeisi A. Projected burden of chronic, noncommunicable diseases in Jordan. Prev Chronic Dis. 2009;6(2):A78.

3. Ritz E, Rychlík I, Locatelli F, Halimi S. End-stage renal failure in type 2 diabetes: a medical catastrophe of worldwide dimensions. Am J Kidney Dis. 1999:34(5):795-808. https://doi.org/10.1016/S0272-6386(99)70035-1.

4. Qi C, Mao X, Zhang Z, Wu H. Classification and differential diagnosis of diabetic nephropathy. J Diabetes Res. 2017;2017:8637138. https://doi.org/1 $0.1155 / 2017 / 8637138$.

5. Wu AY, Kong NC, de Leon FA, Pan CY, Tai TY, Yeung VT, Yoo SJ, Rouillon A, Weir MR. An alarmingly high prevalence of diabetic nephropathy in Asian type 2 diabetic patients: the MicroAlbuminuria Prevalence (MAP) Study. Diabetologia. 2005;48:17-26. https://doi.org/10.1007/s00125-004-1599-9.

6. Gheith O, Farouk N, Nampoory N, Halim MA, Al-Otaibi T. Diabetic kidney disease: world wide difference of prevalence and risk factors. J Nephropharmacol. 2015;5(1):49-56. Published 2015 Oct 9

7. Tuttle KR, Bakris GL, Bilous RW, Chiang JL, et al. Diabetic kidney disease: a report from an ADA consensus conference. Diabetes Care. 2014;37(10): 2864-83. https://doi.org/10.2337/dc14-1296.

8. Levin A, Stevens PE, Bilous RW. Kidney disease: improving global outcomes (KDIGO) CKD work group. KDIGO 2012 clinical practice guideline for the evaluation and management of chronic kidney disease. Kidney Int Suppl. 2013:3:1-150

9. Stevens PE, Levin A, Kidney Disease: Improving Global Outcomes Chronic Kidney Disease Guideline Development Work Group Members. Evaluation and management of chronic kidney disease: synopsis of the kidney disease: improving global outcomes 2012 clinical practice guideline. Ann Intern Med. 2013;158(11):825-30. https://doi.org/10.7326/0003-4819-158-11-2013 06040-00007.

10. Al-Homrany MA, Abdelmoneim I. Significance of proteinuria in type 2 diabetic patients treated at a primary health care center in Abha City, Saudi Arabia. West Afr J Med. 2004;23(3):211-4. https://doi.org/10.4314/wajm.v23 i3.28123.

11. Alzaid AA, Sobki S, De Silva V. Prevalence of microalbuminuria in Saudi Arabians with non-insulin-dependent diabetes mellitus: a clinic-based study. Diabetes Res Clin Pract. 1994;26(2):115-20. https://doi.org/10.1016/0168-822 7(94)90148-1.

12. Herman WH, Aubert RE, Engelgau MM, Thompson TJ, Ali MA, Sous ES, et al. Diabetes mellitus in Egypt: glycaemic control and microvascular and neuropathic complications. Diabet Med. 1998;15(12):1045-51. https://doi. org/10.1002/(SICI)1096-9136(1998120)15:12<1045::AID-DIA696>3.0.CO;2-L.

13. Taleb N, Salti H, Al-Mokaddam M, Merheb M, Salti I, Nasrallah M. Prevalence and determinants of albuminuria in a cohort of diabetic patients in Lebanon. Ann Saudi Med. 2008:28(6):420-5. https://doi.org/10.5144/0256-4 947.2008.420.
14. Sarraf A, Al Dhubaib AS, Al Banai DJ, El Shazly SK, Medhat K. Prevalence of diabetic nephropathy and associated factors in type 2 diabetes mellitus in primary health care in Kuwait. Bull Alex Fac Med. 2005;41:583-91.

15. Pavkov ME, Knowler WC, Bennett PH, Looker HC, Krakoff J, Nelson RG. Increasing incidence of proteinuria and declining incidence of end-stage renal disease in diabetic Pima Indians. Kidney Int. 2006;70(10):1840-6. https://doi.org/10.1038/sj.ki.5001882.

16. Hemmelgarn BR, Zhang J, Manns BJ, Tonelli M, Larsen E, Ghali WA, et al. Progression of kidney dysfunction in the community-dwelling elderly. Kidney Int. 2006;69(12):2155-61. https://doi.org/10.1038/sj.ki.5000270.

17. Lachin JM, Viberti G, Zinman B, Haffner SM, Aftring RP, Paul G, et al. Renal function in type 2 diabetes with rosiglitazone, metformin, and glyburide monotherapy. Clin J Am Soc Nephrol. 2011;6(5):1032-40. https://doi.org/1 0.2215/CJN.09291010.

18. Lee M, Katerelos M, Gleich K, Galic S, Kemp BE, Mount PF, et al. Phosphorylation of acetyl-CoA carboxylase by AMPK reduces renal fibrosis and is essential for the anti-fibrotic effect of metformin. J Am Soc Nephrol. 2018;29(9):2326-36. https://doi.org/10.1681/ASN.2018010050.

19. Kawanami D, Takashi Y, Tanabe M. Significance of metformin use in diabetic kidney disease. Int J Mol Sci. 2020;21(12):4239. Published 2020 Jun 14. https://doi.org/10.3390/ijms21124239.

20. Brenner BM, Cooper ME, de Zeeuw D, Keane WF, Mitch WE, Parving HH, et al. Effects of losartan on renal and cardiovascular outcomes in patients with type 2 diabetes and nephropathy. N Engl J Med. 2001;345(12):861-9. https://doi.org/10.1056/NEJMoa011161.

21. Lewis EJ, Hunsicker LG, Clarke WR, Berl T, Pohl MA, Lewis JB, et al. Renoprotective effect of the angiotensin-receptor antagonist irbesartan in patients with nephropathy due to type 2 diabetes. N Engl J Med. 2001; 345(12):851-60. https://doi.org/10.1056/NEJMoa011303.

22. Parving HH, Andersen $S$, Jacobsen $P$, Christensen PK, Rossing $K$, Hovind $P$, et al. Angiotensin receptor blockers in diabetic nephropathy: renal and cardiovascular end points. Semin Nephrol. 2004;24(2):147-57. https://doi. org/10.1016/j.semnephrol.2003.11.003.

23. Hsu FY, Lin FJ, Ou HT, Huang SH, Wang CC. Renoprotective effect of angiotensin-converting enzyme inhibitors and angiotensin II receptor blockers in diabetic patients with proteinuria. Kidney Blood Press Res. 2017; 42(2):358-68. https://doi.org/10.1159/000477946.

24. Liyanage PLGC, Lekamwasam S, Weerarathna TP, Srikantha DWSY. Prevalence of normoalbuminuric renal insufficiency and associated clinical factors in adult onset diabetes. BMC Nephrol. 2018;19(1):200. Published 2018 Aug 13. https://doi.org/10.1186/s12882-018-1001-7.

25. Penno G, Solini A, Bonora E, Fondelli C, Orsi E, Zerbini G, et al. Clinical significance of nonalbuminuric renal impairment in type 2 diabetes. J Hypertens. 2011;29(9):1802-9. https://doi.org/10.1097/HJH.0b013e32834 $95 \mathrm{~cd} 6$.

26. Kramer HJ, Nguyen QD, Curhan G, Hsu CY. Renal insufficiency in the absence of albuminuria and retinopathy among adults with type 2 diabetes mellitus. JAMA. 2003;289(24):3273-7. https://doi.org/10.1001/jama.289.24.32 73

27. Van Buren PN, Toto R. Hypertension in diabetic nephropathy: epidemiology, mechanisms, and management. Adv Chronic Kidney Dis. 2011;18(1):28-41. https://doi.org/10.1053/j.ackd.2010.10.003.

28. Russo GT, De Cosmo S, Viazzi F, Pacilli A, Ceriello A, Genovese S, et al. Plasma triglycerides and $\mathrm{HDL}-\mathrm{C}$ levels predict the development of diabetic kidney disease in subjects with type 2 diabetes: the AMD annals initiative. Diabetes Care. 2016;39(12):2278-87. https://doi.org/10.2337/dc16-1246.

29. Morton J, Zoungas S, Li Q, Patel AA, Chalmers J, Woodward M, et al. Low HDL cholesterol and the risk of diabetic nephropathy and retinopathy: results of the ADVANCE study. Diabetes Care. 2012;35(11):2201-6. https:// doi.org/10.2337/dc12-0306.

30. Davis TM, Ting R, Best JD, Donoghoe MW, Drury PL, Sullivan DR, et al. Effects of fenofibrate on renal function in patients with type 2 diabetes mellitus: the Fenofibrate Intervention and Event Lowering in Diabetes (FIELD) Study. Diabetologia. 2011;54(2):280-90. https://doi.org/10.1007/s0012 5-010-1951-1.

\section{Publisher's Note}

Springer Nature remains neutral with regard to jurisdictional claims in published maps and institutional affiliations. 